\title{
Spanish version of SPADI (shoulder pain and disability index) in musculoskeletal shoulder pain: a new 10-items version after confirmatory factor analysis
}

\author{
Alejandro Luque-Suarez ${ }^{1 *}$, Antonio Rondon-Ramos², Manuel Fernandez-Sanchez ${ }^{3}$, Kathryn E. Roach ${ }^{4}$
} and Jose Miguel Morales-Asencio ${ }^{5}$

\begin{abstract}
Background: The Shoulder Pain and Disability Index (SPADI) is a tool designed to evaluate the impact of shoulder pathology. The aim of this study was to cross culturally adapt a Spanish version of the SPADI for Spanish population with a musculoskeletal shoulder pain, and to determine the psychometric properties of this instrument using confirmatory factor analysis (CFA).

Methods: Cross-cultural adaptation was performed according to the international guidelines. To assess factor structure, a confirmatory factor analysis was done. Internal consistency was measured using Cronbach's alpha. Item-total and inter-item correlations were assessed. Pearson and Spearman correlations were calculated to assess the convergent validity between SPADI and quick-DASH.

Results: A new Spanish version of SPADI was achieved. The original SPADI factor structure was tested by CFA, obtaining a poor fit: relative chi-square (X2/df) 3.16, CFI 0.89, NFI 0.92, and RMSEA 0.10 (90\% Cl 0.08 to 0.12). An additional model was tested, after deleting items which have had a poor adjustment in the model $(1,11$, and 12), obtaining the best fit: relative chi-square (X2/df) of 1.94, CFI 0.98, NFI 0.95, GFI 0,95, and RMSEA 0.06 (90\% Cl 0.04 to 0.09). The analysis confirmed the bidimensional structure (pain and disability subscales). A correlation Spearman's Rho coefficient of $0.752(p<0.0001)$ and a Cronbach's alpha of 0.90 were obtained.
\end{abstract}

Conclusions: This study validated a new 10-items version of SPADI for Spanish population with musculoskeletal shoulder pain providing a patient reported outcome measure that could be used in both clinical practice and research.

Keywords: Shoulder pain, Diagnostic techniques and procedures

\section{Background}

Shoulder pain is one of the most common musculoskeletal conditions seen in primary care [1], after low back and neck pain. It affects one in three adults [2, 3], accounting $1 \%$ of General Practice consultations in primary care [4]. In working-age populations, the prevalence of shoulder pain associated with musculoskeletal disorders is even higher [5], and increases with age [6].

Shoulder disorders are frequently accompanied by pain and restricted shoulder movement leading to difficulties

\footnotetext{
* Correspondence: aluques@uma.es

'Department of Physical Therapy, University of Malaga, Malaga, Spain

Full list of author information is available at the end of the article
}

in performing certain activities. Recent research suggests that shoulder pain not only affects function during work and leisure time activities, but also may interfere with psychological and social wellbeing [7]. Additionally, environmental factors, such as psychological distress, may contribute to the development of chronic shoulder problems [8].

A variety of musculoskeletal pathologies can cause shoulder pain including subacromial syndrome, frozen shoulder, rotator cuff tendonitis and tear, calcyfying tendonitis, biceps large portion tendonitis, and tear and gleno-humeral instability [9]. 
The impact of shoulder disorders can be assessed in different ways. Traditionally, the assessment has focused on the impairments associated with shoulder pathology by evaluating the range of motion, strength, or pain [10]. However, patients are more concerned with the activity limitations that result from these impairments. This has lead to an increasing emphasis on patient reported outcome (PRO) measures.

The Shoulder Pain and Disability Index (SPADI) is a PRO measure that was developed for use in an outpatient setting. It was designed to measure the impact of shoulder pathology in terms of pain and disability, for both current status, and change on status over time [11]. The SPADI is a self-administered questionnaire that consists of two dimensions, one for pain and the other for functional activities [11]. The pain dimension consists of five questions regarding the severity of an individual's pain. Functional activities are assessed with eight questions. The SPADI takes 5 to $10 \mathrm{~min}$ for a patient to be completed. To answer the questions, subjects place a mark on a " 0 to 10 " numbered scale for each question. Verbal anchors for the pain dimension are 'no pain at all' and 'worst pain imaginable', and those for the functional activities are 'no difficulty' and 'so difficult it required help'. The scores from both dimensions are averaged to produce a total score [11].

The SPADI has been used for measuring the outcomes in different studies and shoulder conditions, such as shoulder pain, various upper extremity diagnoses, various shoulder diagnoses, adhesive capsulitis, rotator cuff, after shoulder arthroplasty, total shoulder arthroplasty, various shoulder surgery, and in different populations and clinical settings, as orthopedic practice, outpatient physiotherapy and community volunteers [12].

The SPADI has been shown to be valid as a measure of pain and disability in community-based patients reporting shoulder pain due to musculoskeletal pathology. The SPADI has good internal consistency with a Cronbach's alpha of 0.95 for the total score, 0.92 for the pain subscale and 0.93 for the disability subscale. The SPADI has also shown ability to detect change over time [13]. In comparing a number of shoulder specific questionnaires in primary care, the SPADI and SRQ (shoulder questionnaire rating) were found to be the most sensitive to detecting change and the SPADI required the least time to complete [14]. Another study reviewing the clinimetric properties of several shoulder questionnaires concluded that SPADI had good construct validity (>0.74) [15].

The increased number of international research projects as well as the diversity of populations and cultures living in a same region, has created the need to validate PRO measures in groups different from those originally used to develop the measure. This requires both translation into a new language and accommodation for differences in cultural characteristics [16].
To our knowledge, only one study has attempted to validate a Spanish language version of the SPADI and this study was conducted in women with shoulder pain following breast cancer surgery rather than shoulder pain due to musculoskeletal pathology [17]. Furthermore, no confirmatory factor analysis has been carried out for any of the multiple versions of SPADI. There is a need of constant update for any PRO measure to guarantee that the mentioned PRO retains all its psychometric properties and its equivalence between original and translated versions, as well as to evaluate its performance in other contexts [18]. This process should be carried out with robust methods, such as confirmatory factor analysis, to test the hypothesis of its original dimensionality. Moreover, the validity of a PRO need to be tested to assess whether its validity is dependent on the population in which the instrument was originally validated, as clinimetric properties many times depend on situational circumstances [18]. Therefore, additional testing in specific populations, i.e., musculoskeletal shoulder pain disorders, need to be carried out.

Hence, the aim of this study is twofold: 1) to translate and validate a Spanish version of the SPADI for Spanish population with a broad range of shoulder disorders and, 2) to determine the psychometric properties of this instrument, using confirmatory methods.

\section{Methods}

\section{Patients and design}

This study was approved by the Ethics Committee of Costa del Sol, March 2014, Spain. All participants in the study gave a written informed consent. Participants were recruited from six primary health care centres in the province of Malaga, Spain. Participants met the following inclusion criteria: i) shoulder pain, defined as "pain in the shoulder region brought on or exacerbated by movement at that shoulder". ii) aged between 18 and 80 years, iii) first language was Spanish (Spain), iv) able to read written Spanish. Participants were excluded from the study if they did not have the capacity to comprehend the questionnaire due to cognitive or emotional impairment. Prior to conducting study, the authors obtained permission for the original author (Dr KE Roach), who was also involved in the study.

\section{The study consisted of two phases}

The study was conducted in two phases. The first was thehe cross-cultural adaptation of the SPADI and the second was the validation of the adapted SPADI. The cross-cultural adaptation process was undertaken using the guidelines and methodology recommended by the International Society for Pharmacoeconomics and Outcomes Research (ISPOR) for the translation and validation of patients reported outcome measures [19]. 
The validation of the adapted SPADI was then undertaken by examining its psychometric properties and conducting a confirmatory factor analysis.

\section{Cross-cultural adaptation}

Cross-cultural adaptation involved eight stages: (1) forward translation, (2) reconciliation; (3) back translation, (4) back translation review, (5) harmonisation, (6) pilot testing/cognitive debriefing, (7) pilot testing review/review of cognitive debriefing results and (8) proofreading.

\section{Forward translation}

Two forward translations in Spanish were undertaken from the original English language version of the SPADI. The translations were undertaken by two independent health professionals who were native residents of Spain and fluent in both Spanish and English.

\section{Forward translation reconciliation}

The two forward translations were reconciled into one version (draft 1) by the two original translators, a third independent translator, and with additional input from the project lead.

\section{Back translation}

Two professional English native translators residing in Spain back translated the reconciled Spanish language version (draft 1) into English independently. The translators had neither prior knowledge of the SPADI nor of the original wording of the English version of the SPADI.

\section{Back translation review}

The principal investigator and a native Spanish speaker fluent in both languages reviewed the back translation for any discrepancies in meaning or terminology used. Any problematic item was discussed until the discrepancies were resolved. This process resulted in a refined second draft of the Spanish translation (draft 2).

\section{Harmonisation}

To produce the final Spanish language translation, a harmonisation meeting was undertaken involving three Spanish translators, the senior investigator and the developer of the original USA version of the SPADI. During this meeting, any discrepancies or issues that were highlighted from the back translation were discussed, the translated version of the SPADI was evaluated and a final version agreed.

\section{Pilot testing/cognitive debriefing}

Once the translation process was completed, the translation was formatted to match precisely the original American language version. The translated SPADI version was initially assessed for comprehensibility in five patient participants, who were Spanish residents and native speakers, met the inclusion criteria described above and had a low educational background without being illiterate. At this stage, each participant was asked by the in-country investigator to carry out the following tasks:

- To complete a copy of the translated SPADI and time needed.

- To comment on the response options within the back-translated SPADI.

- To comment on any wording that was difficult to understand.

- To suggest alternative wording/phrasing for any wording that was difficult to understand.

- To describe in their own words what the wording meant to them. These responses were recorded verbatim and translated into English. The five patients' responses were summarised by the senior investigator. This summary also contained any changes, recommendations or suggestions indicated by the participants and in-country investigators.

\section{Pilot testing review/review of cognitive debriefing results}

To improve the performance of the translated questionnaire, the pilot testing results were reviewed by the incountry investigators. At this stage, any item that caused comprehensibility difficulties for more of the $40 \%$ of the participants was reviewed, and any modifications suggested by the respondent's comments were incorporate to the final translated version.

\section{Proof-reading}

The senior investigator and a translator, who was not involved in the translation process previously, independently proofread the final formatted translation, and any suggested changes were discussed with the senior investigator. Furthermore, the Flesh Reading Ease test and the Flesh Kincaid Grade Level were calculated for readability [20].

Following this process, a final draft of the SPADI translated and culturally adapted into 'Spanish for Spain' was locked down and entered into the cross-cultural validation phase (final draft).

\section{Validation phase}

Before completing the questionnaire, the following data were recorded: age, sex, professional status, education level, affected shoulder and diagnosis. The questionnaires were administered by physical therapists working in the six different physical therapy rooms. They addressed any possible concern of the subjects. Items were numbered from 1 to 13 . Items 1 to 5 were from pain subscale and items 6 to 13 were from disability subscale. 


\section{Sample size calculation}

To test a two-factor model, assuming the null hypothesis of a mean square error of approximation (RMSEA) from 0.04 to 0.085 , with an alpha value of 0.05 , a statistical power of 0.8 and a maximum of 26 degrees of freedom, as suggested by MacCallum et al [21], sample of 196 subjects was required which was over-estimated by $10 \%$ to cover possible losses. The calculations were performed with the Statistica 12 software [22].

\section{Data analysis}

Descriptive statistics were carried out with means, standard deviations, and absolute and relative frequencies. Analysis of normality of distributions was evaluated by the Kolmogorov-Smirnov test, symmetry analysis and kurtosis. Internal consistency was calculated using Cronbach's alpha. A Cronbach's alpha between 0.70 and 0.95 was considered "good" [23]. Moreover, item-total and inter-item correlations were assessed. Pearson and Spearman correlations were calculated to assess the convergent validity between SPADI and quick-DASH-Spanish version [24]. To assess factor structure, a confirmatory factor analysis was done, the evaluated model was fit with the following parameters: the penalizing function (chi square/ df), which is indicative of good fit with values less than 3; Root Mean Square Error of Approximation (RMSEA) and confidence intervals (CI $90 \%$ ), taking the value 0.05 as cut-off of good fit; Normed Fit Index (NFI), the Comparative Fit Index (CFI), and Goodness of Fit Index (GFI) with a minimum value of good fit of 0.90. Multinormality was evaluated with the Mardia's coefficient (multivariate curtosis), which could not be over "p" $(p+2)$, where "p" are the number of observed variables [25]. All the analyses were performed with SPSS 21 [26] and AMOS 21 [27].

\section{Results}

\section{Traslation and cross-cultural adaptation process}

Once a definitive back translation was obtained, the original author (Dr Kathryn Roach) reported some inconsistencies between the translated and original versions. To solve this issue, the expert committee was met, and new items were developed in the final Spanish version.

In the pilot testing phase, results showed no discrepancies in meaning or terminology used in the translated version of the SPADI. Hence, no modification of this version was done. Subjects did not request assistance in interpretating of the questionnaire or any of its items. The time needed to fill out the questionnaire was $4.61 \mathrm{~min}$ (SD 0.99). The result for Flesh Reading Ease test was 56.7, and 7.6 for the Flesh Kincaid Grade Level.

\section{Validation phase}

The final sample consisted of 219 participants, of which, $34.7 \%$ were male and $65.2 \%$ female, with a mean age of
55.08 (SD: 13.63). Characteristics of the sample and their clinical status are described in Table 1.

The original SPADI factor structure was tested by CFA, obtaining a poor fit: relative chi-square $\left(x^{2} / \mathrm{df}\right) 3.16$, CFI 0.89, NFI 0.92, and RMSEA 0.10 (90\% CI 0.08 to 0.12 ). An additional model was tested, after deleting items which have had a bad adjustment in the model $(1,11$, and 12), obtaining the best fit: relative chi-square $\left(x^{2} / \mathrm{df}\right)$ of 1.94 , CFI 0.98, NFI 0.95, GFI 0,95, and RMSEA 0.06 (90\% CI 0.04 to 0.09 ) (Fig. 1). The analysis confirmed the bidimensional structure (pain and disability subscales).

Multinormality test was evaluated with Mardia's coefficient, which obtained a value of 36.3. The global interitem correlations of this new 10 -item version were 0.55 , with a Cronbach's alpha of 0,90 . Item-total statistics are shown in Table 2, being all of them above 0.5 .

The convergent reliability between SPADI and DASH obtained a correlation Spearman's Rho coefficient of $0.752(p<0.0001)$ and an intraclass correlation coefficient of $0.702(p<0.0001)$.

The final 10-items Spanish version of SPADI is shown in Fig. 2.

\section{Discussion}

This study aimed to carry out the cross-cultural adaptation of SPADI for Spanish population and, secondly, to determine the psychometric properties of this version, in a

Table 1 Characteristics of participants

\begin{tabular}{|c|c|c|c|c|}
\hline & & $\begin{array}{l}\text { Female } \\
(n=143)\end{array}$ & $\begin{array}{l}\text { Male } \\
(n=76)\end{array}$ & $p$ \\
\hline Age (years) & & $\begin{array}{l}56.27 \\
\text { (SD 13.27) }\end{array}$ & $\begin{array}{l}52.75 \\
\text { (SD 14.10) }\end{array}$ & 0.073 \\
\hline \multirow{5}{*}{$\begin{array}{l}\text { Professional } \\
\text { status n (\%) }\end{array}$} & Active & $42(52.5)$ & $38(47,5)$ & \multirow[t]{5}{*}{0.001} \\
\hline & Unemployed & $23(74,19)$ & $8(25,81)$ & \\
\hline & Sick-leave & $19(67,86)$ & $9(32,14)$ & \\
\hline & Retired & $37(63,79)$ & $21(36,21)$ & \\
\hline & House-wife & $22(100)$ & $0(0)$ & \\
\hline \multirow{4}{*}{$\begin{array}{l}\text { Educational } \\
\text { level n (\%) }\end{array}$} & Low & $56(73,68)$ & $20(26,32)$ & \multirow[t]{4}{*}{0.247} \\
\hline & Medium & $50(60,98)$ & $32(39,02)$ & \\
\hline & High & $30(58,82)$ & $21(41,18)$ & \\
\hline & Illiteracy & $4(57,14)$ & $3(42,86)$ & \\
\hline \multirow{2}{*}{$\begin{array}{l}\text { Affected shoulder } \\
\text { n (\%) }\end{array}$} & Dominant & $75(60.50)$ & $49(39.50)$ & \multirow[t]{2}{*}{0.118} \\
\hline & Non-dominant & $69(71.10)$ & $28(28.9)$ & \\
\hline \multirow[t]{7}{*}{ Diagnosis n (\%) } & Shoulder pain & $36(63,16)$ & $21(36,84)$ & \multirow[t]{7}{*}{0.505} \\
\hline & Frozen shoulder & $11(84,62)$ & $2(15,38)$ & \\
\hline & Subacromial & $19(70,37)$ & $8(29,63)$ & \\
\hline & Tendon & $29(63,04)$ & $17(36,96)$ & \\
\hline & Surgery & $26(59,09)$ & $18(40,91)$ & \\
\hline & Fracture & $11(68,75)$ & $5(31,25)$ & \\
\hline & Instability & $0(0)$ & $1(100)$ & \\
\hline
\end{tabular}




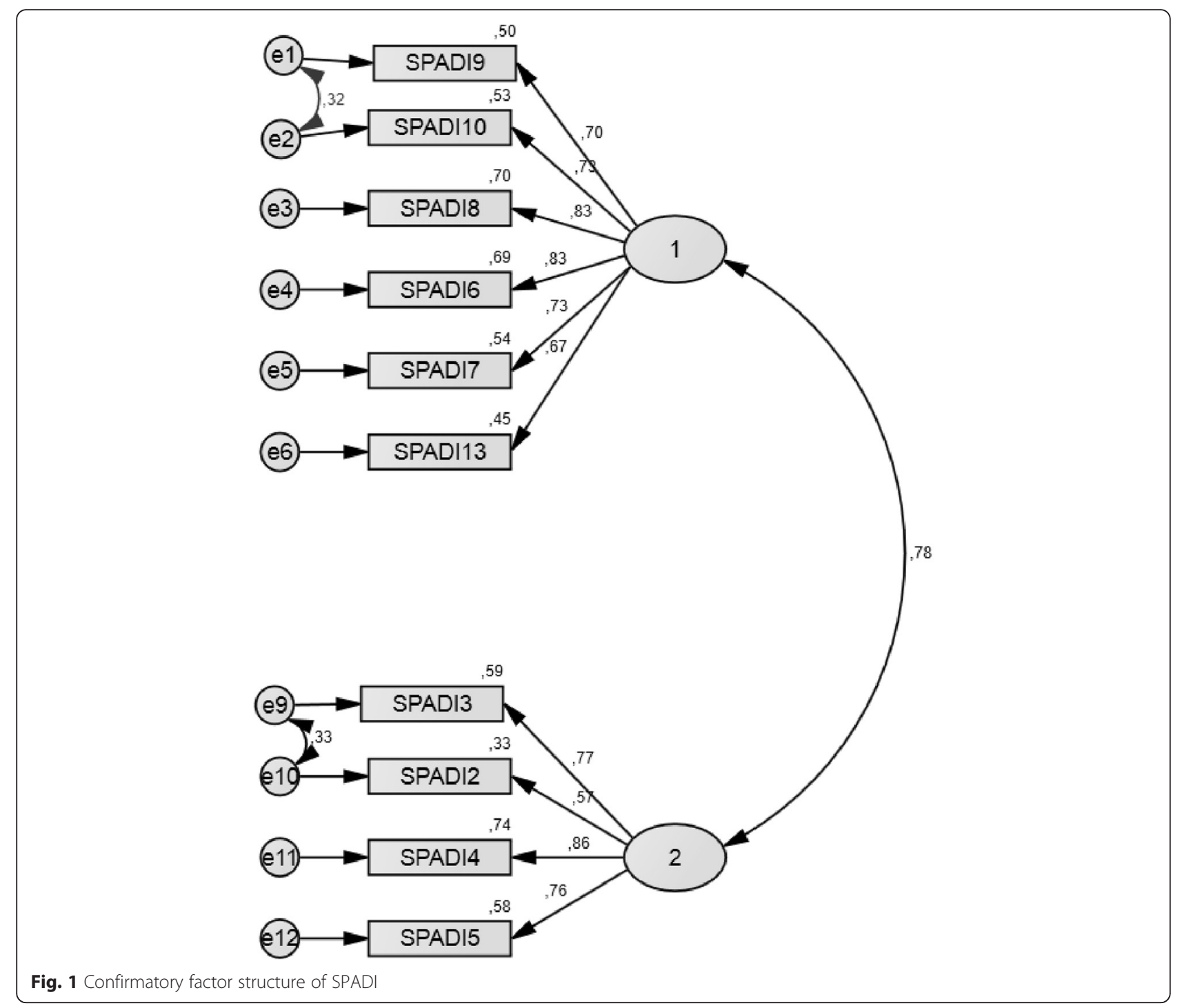

Table 2 Inter-item total statistics

\begin{tabular}{|c|c|c|c|c|c|}
\hline & $\begin{array}{l}\text { Scale mean } \\
\text { if item deleted }\end{array}$ & $\begin{array}{l}\text { Scale variance } \\
\text { if item deleted }\end{array}$ & $\begin{array}{l}\text { Corrected item-total } \\
\text { correlation }\end{array}$ & $\begin{array}{l}\text { Squared multiple } \\
\text { correlation }\end{array}$ & $\begin{array}{l}\text { Cronbach's alpha } \\
\text { if item deleted }\end{array}$ \\
\hline SPADI2 & 49,85 & 424,696 & .515 & .430 & .908 \\
\hline SPADI3 & 49,53 & 415,248 & .678 & .603 & .899 \\
\hline SPADI4 & 50,78 & 398,164 & .724 & .600 & .896 \\
\hline SPADI5 & 50,39 & 404,958 & .650 & .520 & .900 \\
\hline SPADI6 & 51,25 & 383,372 & .754 & .633 & .894 \\
\hline SPADI7 & 49,19 & 408,582 & .671 & .527 & .899 \\
\hline SPADI8 & 50,89 & 397,198 & .755 & .630 & .894 \\
\hline SPADI9 & 53,35 & 403,221 & .644 & .562 & .901 \\
\hline SPADI10 & 53,21 & 397,261 & .687 & .587 & .898 \\
\hline SPADI13 & 51,18 & 393,603 & .636 & .426 & .902 \\
\hline
\end{tabular}




\section{INDICE DE DOLOR Y DISCAPACIDAD DEL HOMBRO}

Por favor, marque sobre la casilla que mejor representa su experiencia durante la última semana en relación a su problema de hombro

\section{ESCALA DE DOLOR}

\section{A. ¿Qué intensidad tiene su dolor?}

Marque el número que mejor describe su dolor, siendo: $0=$ no dolor y $10=$ el peor dolor imaginable

\begin{tabular}{|l|l|l|l|l|l|l|l|l|l|l|l|}
\hline Cuando está tumbado del lado del hombro malo & 0 & 1 & 2 & 3 & 4 & 5 & 6 & 7 & 8 & 9 & 10 \\
\hline
\end{tabular}

\begin{tabular}{|l|l|l|l|l|l|l|l|l|l|l|l|l|}
\hline Para coger algo de una estantería en alto & 0 & 1 & 2 & 3 & 4 & 5 & 6 & 7 & 8 & 9 & 10 \\
\hline Al & 0 & 1 & 2 & 3 & 4 & 5 & 6 & 7 & 8 & 9 & 10 \\
\hline
\end{tabular}

\begin{tabular}{|l|l|l|l|l|l|l|l|l|l|l|l|}
\hline Al tocarse detrás del cuello & 0 & 1 & 2 & 3 & 4 & 5 & 6 & 7 & 8 & 9 & 10 \\
\hline
\end{tabular}

\begin{tabular}{|l|l|l|l|l|l|l|l|l|l|l|l|}
\hline Empujar con el brazo del hombro malo & 0 & 1 & 2 & 3 & 4 & 5 & 6 & 7 & 8 & 9 & 10 \\
\hline
\end{tabular}

\section{ESCALA DE DOLOR}

B. ¿Qué dificultad tiene para hacer cosas como?

Marque el número que mejor describe lo que le pasa, siendo: $0=\sin$ dificultad y $10=\tan$ difícil que requiere ayuda

\begin{tabular}{|l|l|l|l|l|l|l|l|l|l|l|l|}
\hline Lavarse la cabeza & 0 & 1 & 2 & 3 & 4 & 5 & 6 & 7 & 8 & 9 & 10 \\
\hline Lavarse la espalda & 0 & 1 & 2 & 3 & 4 & 5 & 6 & 7 & 8 & 9 & 10 \\
\hline Ponerse una camiseta o un jersey & 0 & 1 & 2 & 3 & 4 & 5 & 6 & 7 & 8 & 9 & 10 \\
\hline Ponerse una camisa con los botones por delante & 0 & 1 & 2 & 3 & 4 & 5 & 6 & 7 & 8 & 9 & 10 \\
\hline Ponerse unos pantalones & 0 & 1 & 2 & 3 & 4 & 5 & 6 & 7 & 8 & 9 & 10 \\
\hline Sacarse algo del bolsillo trasero & 0 & 1 & 2 & 3 & 4 & 5 & 6 & 7 & 8 & 9 & 10 \\
\hline
\end{tabular}

Fig. 2 10-items Spanish language version of the SPADI

population of patients suffering from shoulder pain. Regarding the first objective, the cross-cultural adaptation, our study encountered a few problems during the translation process, primarily in related to time period reference in the instructions. These problems were solved by the research team and the original author. The participants had no difficulty comprehending the questionnaire during the pilot study, and the translated version demonstrated good results in readability tests. We modified the original 13 item English language version of the SPADI by deleting those items with low correlations (items 1, 11 and 12). The confirmatory factor analysis for this new version attained the best fit. There was a strong correlation between the new Spanish Language SPADI and the Quick-Dash demonstrating good convergent validity. One of the strengths of this study was the scientific rigour of the methods used during the cross-cultural adaption phase. This included involving the original author to ensure the accuracy of the translation process. A previous study to adapt a new Spanish version of SPADI has been done recently [17]. These authors did not find any significant problems and/or difficulties in the cross-cultural adaptation process. The lack of difficulties in comprehension for the participants during the cross-cultural process is consistent with other studies [17, 28, 29]. Moreover, our new Spanish language version achieved good readability. The time required to complete the new Spanish Language SPADI are similar to the original version [11], although other cross-cultural versions have reported even less time to complete [29].

Regarding the psychometric properties, this is the first study of a Spanish language version of SPADI to utilize a factor structure analysis, with confirmatory methods. As a result of our structure factor analysis, items 1 ("How severe is your pain at your worst"), 11 ("Placing an object on a high shelf") and 12 ("How much difficult do you have carrying a heavy object of 10 pounds") were eliminated to achieve the best adjustment for the model. As a result, the new Spanish version for SPADI has different pain and disability subscales than the original English language version. Other studies have reported a unidimensional structure, without differences between pain and disability subscales [30, 31], while others were in consistent with the original version (two subscales) [32]. Based on our results, we recommend the use of this new 10-item Spanish SPADI-version.

The internal consistency of our version of the SPADI was good (Cronbach's alpha of 0.90 ) was consistent with the findings of Torres-Lacomba et al [17], who also reported good values in internal consistency (0.96). It is important to note that the sample for Torres-Lacomba study was very different from the sample for our study in that it was drawn from women with shoulder pain after breast cancer surgery. Similar to other cross-cultural studies on SPADI [30-32], we found a strong correlation between the SPADI and the Quick-DASH indicating good 
convergent validity. Alsanawi et al [33] found a correlation between the SPADI and DASH of 0.84 (Spearman coefficient), while Ebrahimzadeh et al [28] reported a correlation of 0.61 .

Our results imply that a new 10-items Spanish version for SPADI could be used by researchers and clinicians as a self-reported disability measure in patients suffering from shoulder pain in both routine clinical practice or in clinical research trials, This version keeps the properties of the original version, with two subscales (pain and disability). Spanish language is one of the most spoken languages around the world. Even though different Spanish speaker countries present some differences, semantic and grammatical rules are homogeneus, so that the version presented in this study could be of reference for other cross-cultural studies on SPADI, requiring only minor changes to adapt wording to accommodate the specific terms used in informal language. This new index could permit comparisons between other countries when studies on shoulder pain will be carried out.

However, there are some limitations in this study that should need to be recognized. Firstly, psychometric properties for Spanish-SPADI such as test-retest reliability, sensibility to change, as well as divergent validity have not been determined. The variety of different shoulder pain conditions in the participant sample could mean a risk of bias. Nevertheless, recent literature [34] recommends to avoid the use of subgroups in shoulder pain due to the lack of a gold standard for each of the diagnostic labels. The present study did no distinguish between participants with acute versus chronic shoulder pain and this might have influenced our findings so they must be taken with caution. Future investigations should be conducted to determine cutpoints in the score of this new version that could be used to classify patients with mild, moderate and/or severe shoulder pain.

\section{Conclusions}

This study carried out a cross-cultural adaptation and validation of Spanish language version of the SPADI for Spanish population, and an examination of the psychometric properties of this new version. This study validated a new 10-items version of SPADI for Spaniards providing a patient reported outcome measure for use in this population in both clinical practice and research.

\section{Ethics approval and consent to participate}

Ethics Committee of Costa del Sol in March 2014, Spain, approved this study ( $n^{\circ} 011$ marzo_PR). All participants in the study gave a written informed consent.

\section{Abbreviations}

CFA: confirmatory factor analysis; CFI: the comparative fit index; $\mathrm{Cl}$ : confidence intervals; DASH: disability of arm, shoulder and hand questionnaire; GFI: goodness of fit index.; NFI: normed fit index; PRO: patient reported outcome; RMSEA: root mean square error of approximation; SPADI: shoulder pain and disability index.

\section{Competing interests}

The authors declare that they have no competing interests.

\section{Authors' contributions}

Conception and design: ALS. Data analysis and interpretation: ALS, JMMA. Collection and assembly of data: ARR, MFS. Manuscript writing: ALS, AR, KER, JMMA. Final approval of manuscript: ALS, ARR, MFS, KER, JMMA.

\section{Acknowledgments}

We would like to thank physical therapy students Francia Bedoya, Laura Lopez, and Javier Lopez for their contribution in the recruitment phase of this study, and also to all the physical therapists of the Costa del Sol Health District, Malaga, Spain, involved in this study.

\section{Funding}

This study was no funded.

\section{Author details}

${ }^{1}$ Department of Physical Therapy, University of Malaga, Malaga, Spain. ${ }^{2}$ Las Lagunas Primary Health Care Center, Costa del Sol Sanitary District, Fuengirola-Mijas, Spain. ${ }^{3}$ Department of Nursing, Physical Therapy and Medicine, University of Almeria, Almeria, Spain. ${ }^{4}$ Department of Physical Therapy, Miller School of Medicine, University of Miami, Miami, USA.

${ }^{5}$ Department of Nursing, University of Malaga, Malaga, Spain.

Received: 22 October 2015 Accepted: 23 February 2016

Published online: 01 March 2016

\section{References}

1. Urwin $M$, Symmons $D$, Allison $T$, Brammah $T$, Busby $H$, Roxby $M$, Simmons $A$, Williams G. Estimating the burden of musculoskeletal disorders in the community: the comparative prevalence of symptoms at different anatomical sites, and the relation to social deprivation. Ann Rheum Dis. 1998;57:649-55.

2. Chard MD, Hazleman R, Hazleman BL, King RH, Reiss BB. Shoulder disorders in the elderly: a community survey. Arthritis Rheum. 1991;34:766-9.

3. Van der Heijden GJ. Shoulder disorders: a state-of-the-art review. Baillieres Best Pract Res Clin Rheumatol. 1999;13:287-309.

4. van der Windt D a, Koes BW, de Jong B a, Bouter LM. Shoulder disorders in general practice: incidence, patient characteristics, and management. Ann Rheum Dis. 1995:54:959-64.

5. Roquelaure $\mathrm{Y}, \mathrm{Ha}$ C, Leclerc A, Touranchet A, Sauteron M, Melchior M, Imbernon E, Goldberg M. Epidemiologic surveillance of upper-extremity musculoskeletal disorders in the working population. Arthritis Care Res. 2006:55:765-78.

6. Linsell L, Dawson J, Zondervan K, Rose P, Randall T, Fitzpatrick R, Carr a. Prevalence and incidence of adults consulting for shoulder conditions in UK primary care; patterns of diagnosis and referral. Rheumatology. 2006;45:215-21.

7. Schmidt S, Ferrer M, González M, González N, Valderas JM, Alonso J, Escobar A, Vrotsou K. Evaluation of shoulder-specific patient-reported outcome measures: a systematic and standardized comparison of available evidence. J Shoulder Elb Surg. 2014:23:434-44.

8. Badcock LJ, Lewis M, Hay EM, McCarney R, Croft PR. Chronic shoulder pain in the community: a syndrome of disability or distress? Ann Rheum Dis. 2002;61:128-31.

9. Varela E, Valero R, Küçükdeveci a a, Oral A, llieva E, Berteanu M, et al. Shoulder pain management. The role of physical and rehabilitation medicine physicians. The European perspective based on the best evidence. A paper by the UEMS-PRM section professional practice committee. Eur J Phys Rehabil Med. 2013;49:743-51.

10. Desai AS, Dramis A, Hearnden AJ. Critical appraisal of subjective outcome measures used in assessment of shoulder disability. Ann R Coll Surg Engl. 2010:92:9-13.

11. Roach KE, Budiman-Mak E, Songsiridej N, Lertratanakul Y. Development of a shoulder pain and disability index. Arthritis Care Res. 1991;4:143-9.

12. Angst F, Schwyzer HK, Aeschlimann A, Simmen BR, Goldhahn J. Measures of adult shoulder function: Disabilities of the Arm, Shoulder, and Hand Questionnaire (DASH) and Its Short Version (QuickDASH), Shoulder Pain and 
Disability Index (SPADI), American Shoulder and Elbow Surgeons (ASES) Society Standardized Shoulder. Arthritis Care Res. 2011;63 Suppl 11:174-88.

13. MacDermid JC, Solomon P, Prkachin K. The Shoulder Pain and Disability Index demonstrates factor, construct and longitudinal validity. BMC Musculoskelet Disord. 2006;7:12.

14. Paul A, Lewis M, Shadforth MF, Croft PR, Van Der Windt D a WM, Hay EM. A comparison of four shoulder-specific questionnaires in primary care. Ann Rheum Dis. 2004;63:1293-9.

15. Bot SDM, Terwee CB, van der Windt D a WM, Bouter LM, Dekker J, de Vet HCW. Clinimetric evaluation of shoulder disability questionnaires: a systematic review of the literature. Ann Rheum Dis. 2004;63:335-41.

16. Acquadro C, Conway K, Hareendran A, Aaronson N, Group ERI and Q of LA (ERIQA). Literature review of methods to translate health-related quality of life questionnaires for use in multinational clinical trials. Value Heal. 2008:11:509-21.

17. Torres-Lacomba M, Sánchez-Sánchez B, Prieto-Gómez V, Pacheco-da-Costa S, Yuste-Sánchez MJ, Navarro-Brazález B, Gutiérrez-Ortega C. Spanish cultural adaptation and validation of the shoulder pain and disability index, and the oxford shoulder score after breast cancer surgery. Health Qual Life Outcomes. 2015:13:63.

18. de Vet HCW, Terwee CB, Bouter LM. Current challenges in clinimetrics. J Clin Epidemiol. 2003;56:1137-41.

19. Wild D, Grove A, Martin M, Eremenco S, McElroy S, Verjee-Lorenz A, Erikson P. Principles of good practice for the translation and cultural adaptation process for Patient-Reported Outcomes (PRO) measures: report of the ISPOR task force for translation and cultural adaptation. Value Heal. 2005;8:95-104.

20. Readability [https://readability-score.com/]

21. MacCallum R, Lee T, Browne MW. The issue of isopower in power analysis for tests of structural equation models. Struct Equ Model A Multidiscip J. 2010:17:23-41.

22. Statistica [http://www.statsoft.com/Products/STATISTICA/Product-Index].

23. Terwee CB, Bot SDM, de Boer MR, van der Windt D a WM, Knol DL, Dekker J, Bouter LM, de Vet HCW. Quality criteria were proposed for measurement properties of health status questionnaires. J Clin Epidemiol. 2007;60:34-42.

24. Rosales RS. Quick-DASH Spanish version. 2006.

25. Bollen KA. Structural Equations with Latent Variables. 1989.

26. Stats 21 [http://www-01.ibm.com/software/es/stats21/].

27. Amos [http://www-03.ibm.com/software/products/es/spss-amos].

28. Ebrahimzadeh MH, Birjandinejad A, Golhasani F, Moradi A, Vahedi E, Kachooei AR. Cross-cultural adaptation, validation, and reliability testing of the Shoulder Pain and Disability Index in the Persian population with shoulder problems. Int J Rehabil Res. 2013;2014:1-4.

29. Angst F, Goldhahn J, Pap G, Mannion a F, Roach KE, Siebertz D, Drerup S, Schwyzer HK, Simmen BR. Cross-cultural adaptation, reliability and validity of the German Shoulder Pain and Disability Index (SPADI). Rheumatology (Oxford). 2007;46:87-92.

30. Jamnik $H$, Spevak MK. Shoulder pain and disability index: validation of Slovene version. Int J Rehabil Res. 2008:31:337-41.

31. Tveitå EK, Ekeberg OM, Juel NG, Bautz-Holter E. Responsiveness of the shoulder pain and disability index in patients with adhesive capsulitis. BMC Musculoskelet Disord. 2008;9:161.

32. Hill CL, Lester S, Taylor AW, Shanahan ME, Gill TK. Factor structure and validity of the shoulder pain and disability index in a population-based study of people with shoulder symptoms. BMC Musculoskelet Disord. 2011;12:8.

33. Alsanawi HA, Alghadir A, Anwer S, Roach KE, Alawaji A. Cross-cultural adaptation and psychometric properties of an Arabic version of the Shoulder Pain and Disability Index. Int J Rehabil Res. 2015;38:270-5.

34. Schellingerhout JM, Verhagen AP, Thomas S, Koes BW. Lack of uniformity in diagnostic labeling of shoulder pain: Time for a different approach. Man Ther. 2008;13:478-83.

\section{Submit your next manuscript to BioMed Central and we will help you at every step:}

- We accept pre-submission inquiries

- Our selector tool helps you to find the most relevant journal

- We provide round the clock customer support

- Convenient online submission

- Thorough peer review

- Inclusion in PubMed and all major indexing services

- Maximum visibility for your research

Submit your manuscript at www.biomedcentral.com/submit

) Biomed Central 